\title{
VIOLENCE ON HEALTH WORKERS AT THE WORKPLACE AND ITS MANAGEMENT STRATEGY: A SYSTEMATIC REVIEW
}

\author{
Nuril Rahmatika'), Mardiati Nadjibº \\ 1)Masters Program in Public Health, Universitas Indonesia \\ 2)Department of Health Policy Administration, Faculty of Public Health, Universitas Indonesia
}

\begin{abstract}
Background: Healthcare workers at workplace frequently face with patients becoming violent because of undesired events such as a long wait. Globally, workplace violence is a major challenge to safety for health workers, involving significant consequences to the victims, patients, and healthcare organizations. This study aimed to systematically review violence on health workers at the workplace and its management strategy.

Subjects and Method: A systematic review was conducted by searching published articles from 2015 to 2019 including ProQuest, Springer Link, and Scopus. The keyword for this review was "prevalence" AND "risk factor" AND "workplace violence" AND "hospital". The inclusion criteria were English, open acces, health worker, and cross-sectional. After review process, 14 articles were included in this study. Results: Violence was affected by age of the victim, lack of courage to report incidents of violence, work experience, direct interaction with patients, feeling of worry / anxiety, shift system, and night work. Two articles stated lack of courage to report incidents of violence as a predictor. Three articles stated reporting as a futile act as a cause of under reporting. An article stated that the institution had taken necessary steps and provided encouragement to report act of violence, as well as had chosen strategies to prevent violence, including security measure, protocol, and training related to violence in the workplace.

Conclusion: Violence is often found in health workers in the workplace. Violence was affected by age of the victim, lack of courage to report incidents of violence, work experience, direct interaction with patients, feeling of worry/anxiety, shift system, and night work. Improving management in health care facilities is needed to prevent and deal with workplace violence.
\end{abstract}

Keywords: violence, workplace, health workers.

\section{Correspondence:}

Nuril Rahmatika. Masters Program in Public Health, Universitas Indonesia. Depok, West Java. Email: nurilrahmatika7891@gmail.com. Mobile: 081280839382.

\section{BACKGROUND}

$\overline{\text { Profession who has a high risk of experien- }}$ cing violence is health personnels from patients and visitors. Based on The National Crime Victimization Survey, health personnels have a 20\% higher risk of experiencing workplace violence than other workers (The Joint Commission, 2018).

Workplace violence can be experienced by health personnels in all health care centers (Kocabiyik et al., 2015).

The notion of workplace violence put forward by The National CDC Institute for Safety and Health (NIOSH) is an act of violence (including physical violence and threats of violence) to someone at work or while on duty (The Joint Commission, 2018).

According to the World Health Organization (WHO), workplace violence is an incident where staff are harassed, threatened, and attacked in circumstances related to their work, travel to and from work, which involve explicit and implicit challenges and to security, welfare, and health. Workplace violence can affect quality of health services (Cheung and Yip, 2017).

Workplace violence experienced by health personnels is a problem faced in va- 
rious countries around the world. From an international study, it was found that the incidence of workplace violence in nurses in the Hospital environment has a prevalence of $10 \%-50 \%$, up to $87 \%$ (Cheung and Yip, 2017).

In a study conducted in several countries, it was found that the profession that has a high risk compared to other professions, both from the health sector or other sectors, which are vulnerable to violence is nurses. In Turkey, workplace violence is not just physical and psychological violence, but also to the murder of health personnels (Aksakal et al, 2015).

Reporting of acts of violence is often not done by health personnels. Several things caused the lack of reporting related to reporting procedures. Even though they have reporting procedures, not all health personnels know how to utilize those (Peng Li et al., 2018).

To find out the prevention of violence in the right workplace, it is first necessary to know about various risk factors that cause violence. In addition, it is necessary to know the efforts or strategies that have been implemented by health service providers to become a reference for other health service providers.

\section{SUBJECTS AND METHOD}

This systematic review was conducted by using PRISMA. Authors searched for articles through an online database, namely ProQuest, Springer Link, and Scopus with keywords "prevalence" AND "risk factor" AND "workplace violence" AND "hospital".

The inclusion criteria for this systematic review were articles published from 2015-2019, English, open access, health per- sonnels, and cross-sectional design. The exclusion criteria used were study on health students, such as koas or nursing students and topics other than workplace violence.

Articles found after entering keywords were 874 articles. The next step was to filter out the articles that would be used by making arrangements for the past five years, the field of public health, and open access. The final step taken was screening of titles and abstracts according to inclusion criteria and relevance to the study objectives. The number of articles that were reviewed was 14 articles. The steps in the search for articles to the discovery of articles to be explored are explained in Figure 1.

\section{RESULTS}

From an article search on three databases with predetermined keywords, 874 articles were found with 14 relevant articles. The study sites are Macau, Serbia, Hong Kong, Taiwan, China, Saudi Arabia, Egypt, Palestine, and India. All articles used in this systematic review use a cross-sectional design by distributing questionnaires to health personnels, both medical and/or non-medical personnel.

In fourteen articles reviewed, it was known that health personnels have experienced violence at work. Workplace violence in the form of physical or non-physical violence committed by the patient or a patient's relative.

Factors that have a significant influence on most articles were the health profession/clinician (Articles no. 2, 3, 5, 7, 8, 10, 11, and 13), age (Articles no. 5, 7, 9, 10, 11,13 , 14), shift work systems (Articles no. 1, 2, 3, 4, $6,10,12$ ), and work experience (Articles no. $1,4,8,9,11,12,13)$. 


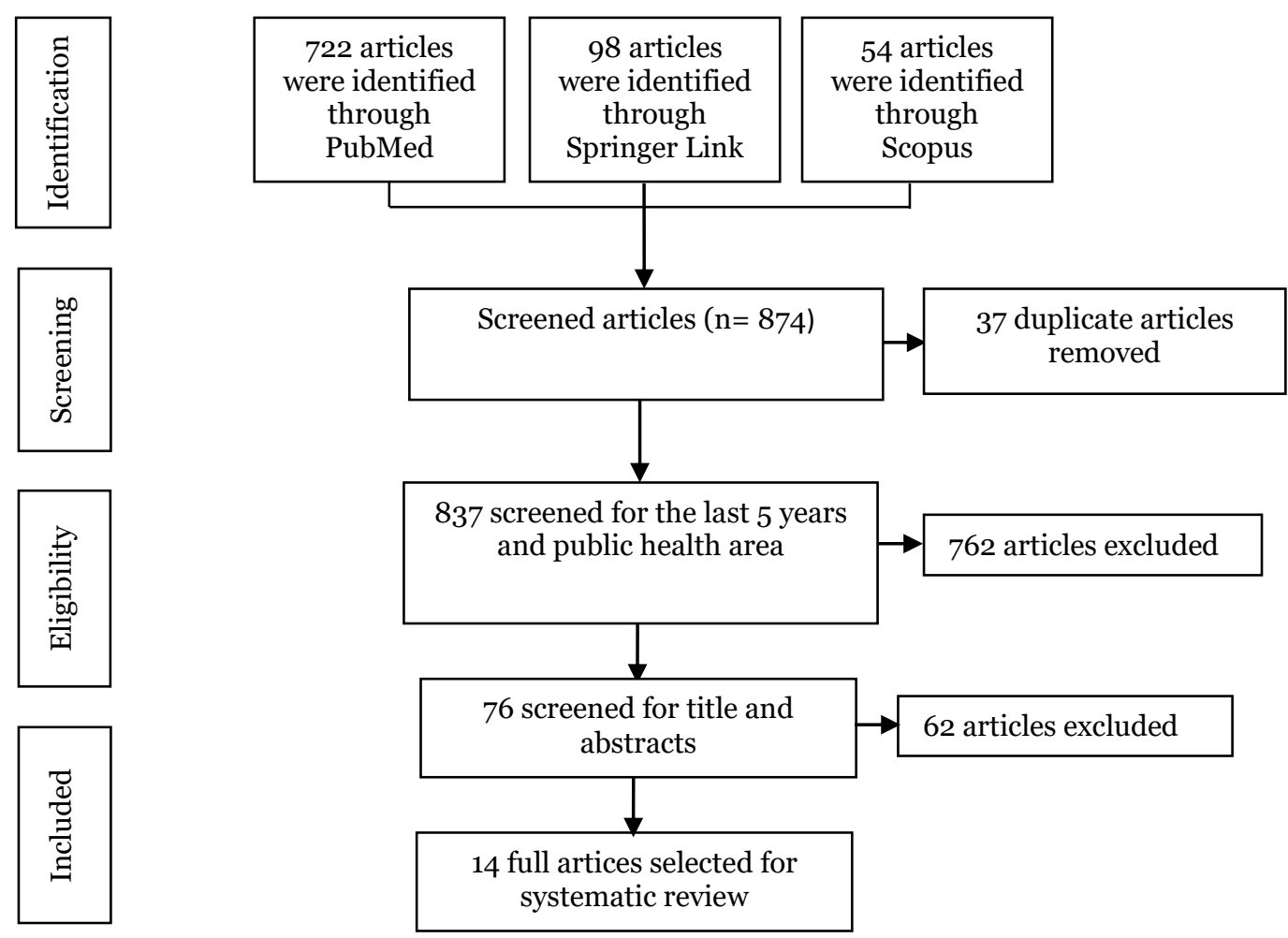

Figure 1. PRISMA Flow Diagram

Five of the fourteen articles mention factors that influence workplace violence were interactions with patients. Four of the fourteen articles mention factors that influence violence in the workplace were worry about violence. Three of the fourteen articles mentioned factors that influence workplace violence were the department or work environment of health personnels and/or professional titles.

Two of the fourteen articles mentioned factors that influence workplace violence were lack of support to report acts of violence, education level, and/or gender. Factors on the number of employees in a work environment, job satisfaction, problems with colleagues, self-harm, treatment time, income, and/ or marital status are found in one of fourteen articles.

In three articles, it was mentioned that reporting violence was a useless action. In one article, it was mentioned that health service institutions had implemented strategies to overcome violence in the workplace. The strategy was the existence of a security system in health care institutions, preparation of patient protocols, and implementation of training for health personnels. 
Table 1. Article Search Results

\begin{tabular}{|c|c|c|c|c|c|c|}
\hline No & Author (Year) & Title & Place & Design & $\begin{array}{l}\text { Results } \\
\end{array}$ & $\begin{array}{c}\text { Conclusions } \\
\end{array}$ \\
\hline 1 & $\begin{array}{l}\text { Cheung et al. } \\
(2017)\end{array}$ & $\begin{array}{l}\text { Workplace Violence } \\
\text { toward Physicians } \\
\text { and Nurses: } \\
\text { Prevalence and } \\
\text { Correlates in } \\
\text { Macau }\end{array}$ & Macau & $\begin{array}{l}\text { Cut } \\
\text { Latitude }\end{array}$ & $\begin{array}{l}\text { Out } 720 \text { health personnels, } 57.2 \% \text { have } \\
\text { experienced workplace violence. Some factors } \\
\text { that have a significant influence were work } \\
\text { experience, direct service to patients, shift } \\
\text { work systems, and anxiety over acts of } \\
\text { violence. Not all nurses reported acts of } \\
\text { violence they experienced. }\end{array}$ & $\begin{array}{l}\text { Workplace violence is an occupational } \\
\text { hazzard in Macau for general practitioners } \\
\text { and nurses. Therefore, training needs to be } \\
\text { carried out related to de-escalation skills in } \\
\text { dealing with violence. Coping strategies need } \\
\text { to be possessed by doctors and nurses as } \\
\text { health workers who have high interactions } \\
\text { with patients to reduce psychological impacts. }\end{array}$ \\
\hline 2 & $\begin{array}{l}\text { Marina et al. } \\
(2017)\end{array}$ & $\begin{array}{l}\text { Encouraging } \\
\text { employees to report } \\
\text { verbal violence in } \\
\text { primary health care } \\
\text { in Serbia: A cross- } \\
\text { sectional study }\end{array}$ & $\begin{array}{l}\text { Belgrade, } \\
\text { Serbia }\end{array}$ & $\begin{array}{l}\text { Potong } \\
\text { Lintang }\end{array}$ & $\begin{array}{l}\text { From a total of } 1,526 \text { participants, } 47.8 \% \text { had } \\
\text { experienced verbal abuse at work. The most } \\
\text { common perpetrators of violence are patients. } \\
\text { Factors that have contributed to verbal abuse } \\
\text { are the profession of nurses, night watch, in- } \\
\text { teractions with patients, number of em- } \\
\text { ployees, and lack of support to report acts of } \\
\text { violence. The lack of reporting among others } \\
\text { was caused by the assumption that reporting } \\
\text { was a futile act, reporting was not an } \\
\text { important thing, and it was not known which } \\
\text { reporting was aimed at. }\end{array}$ & $\begin{array}{l}\text { The high prevalence of verbal violence can } \\
\text { have a negative impact. To reduce the } \\
\text { prevalence can be done by improveing } \\
\text { procedures in the organization and increasing } \\
\text { the urge to report the occurrence of verbal } \\
\text { violence. }\end{array}$ \\
\hline 3 & $\begin{array}{l}\text { Cheung and Yip } \\
\text { (2017) }\end{array}$ & $\begin{array}{l}\text { Workplace Violence } \\
\text { towards Nurses in } \\
\text { Hongkong: } \\
\text { prevalence and } \\
\text { correlates }\end{array}$ & Hongkong & $\begin{array}{l}\text { Cut } \\
\text { Latitude }\end{array}$ & $\begin{array}{l}\text { Of a total sample of } 850 \text { nurses, } 44.6 \% \text { had } \\
\text { experienced violence at work. Violence was } \\
\text { most often done by patients. Factors that } \\
\text { significantly influenced were the clinician, } \\
\text { shift work, job satisfaction, and problems } \\
\text { with colleagues, tendency to self-harm, and } \\
\text { anxiety. Not all nurses who experience acts of } \\
\text { violence report to their superiors. }\end{array}$ & $\begin{array}{l}\text { Workplace violence is an occupational hazard } \\
\text { for nurses in Hong Kong. } \\
\text { Health service providers and health } \\
\text { personnels need to form a strategy to prevent } \\
\text { incidents of violence in the health service } \\
\text { environment. Health authorities need to } \\
\text { develop reporting systems that are easy to } \\
\text { understand and implement a zero tolerance } \\
\text { policy to prevent incidents of violence in the } \\
\text { workplace. }\end{array}$ \\
\hline 4 & Niu et al. (2019) & $\begin{array}{l}\text { Prevalence of } \\
\text { workplace violent } \\
\text { episodes } \\
\text { experienced by } \\
\text { nurses in acute }\end{array}$ & $\begin{array}{l}\text { Northern } \\
\text { Taiwan }\end{array}$ & $\begin{array}{l}\text { Cut } \\
\text { Latitude }\end{array}$ & $\begin{array}{l}\text { Of the total sample of } 429 \text { nurses, } 88.3 \% \text { had } \\
\text { experienced violence. The factor that } \\
\text { contributes to physical and psychological } \\
\text { violence was the shift work system while } \\
\text { nurses who have } 5-10 \text { work experience on }\end{array}$ & $\begin{array}{l}\text { Psychiatric nurses have experienced physical } \\
\text { and psychological abuse in the past } 12 \\
\text { months. Institutions need to do multilevel } \\
\text { actions to create a comfortable environment } \\
\text { and can reduce the incidence of violence in }\end{array}$ \\
\hline
\end{tabular}

The $6^{\text {th }}$ International Conference on Public Health Best Western Premier Hotel, Solo, Indonesia, October 23-24, 2019 | 149 https://doi.org/10.26911/the6thicph-FP.02.05 
$5 \quad$ Li et al. (2018) Physical violence against general practicioners and nurses in Chinese township hospitals: incidence and implications

$6 \quad$ Al-Turki et al. (2016)

Violence against health workers in Family Medicine Centers
Provinsi

Heilongjiang,

China

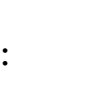

$\begin{array}{ll}\text { Riyadh, Saudi } & \text { Cut } \\ \text { Arabia } & \text { Latitude }\end{array}$

Cut though most stated that they had procedures, but not all of them understood how to report them. Only a small number of participants said that they had received training to deal with acts of aggression from perpetrators of violence. Some factors that have a significant influence were age, general nurses, and higher professional degrees.

Of the total 270 participants, $45.6 \%$ had experienced violence at work. More violence was done by patients. Factors that have an influence were afternoon or night duty, shift work, and lack of support to report violence. Most victims did not report acts of violence because they believe that reporting was not an efficient action.

Provinsi Cut

Physical Violence against General

Practitioner s and

Nurses in Chinese

Heilongjiang, Latitude

China

a total of 840 respondents, $12.6 \%$ had experienced physical violence. The most physical acts of violence were the relatives of patients. Only a few reported incidents of
The total sample was 840 people. Even

Hospitals: A CrossSectional Survey psychological violence. Lack of reporting of incidents of violence due to the presumption

of vain and not important actions. Most respondents said that there had been steps to report incidents of violence and the incentive to report incidents of violence. The strategy of the institution to prevent workplace violence was to have a security system, protocol development, and training.

the workplace. violence because reporting actions were deemed useless. Although there were reporting procedures, not all health personnels understand the procedures. Factors that have a significant influence were general nurses, age $<35$ years old, a higher professional degree, and direct interaction with patients.
Physical violence in Chinese Township Hospitals is an occupational hazard. A strategy for formulating policies, procedures and interventions needs to be made to deal with incidents of violence in the workplace.

Workplace violence is still a problem in primary health care. With the implementation of programs and training for health personnels, an efficient reporting system (policies and procedures), and the implementation of a zero tolerance policy is expected to reduce violence among health personnels.

Physical violence is an occupational hazard that is a public health problem in Chinese Township Hospitals. Strategic policies, procedures and interventions are needed to deal with the case.

The $6^{\text {th }}$ International Conference on Public Health Best Western Premier Hotel, Solo, Indonesia, October 23-24, $2019 \mid 150$ https://doi.org/10.26911/the6thicph-FP.02.05 
Li et al. (2017)

Workplace violence

against medical

staff of Chinese

children's

hospitals: A cross-

sectional study

A cross-sectional study on the associated risk

factors

for workplace

violence against

Chinese nurses

$10 \quad$ Sun et al. (2017)

Workplace violence against health care workers in north

chinese hospitals: A

cross-sectional

survey

11 Abdella and Salama (2017)

Prevalence and risk factors

of workplace

violence against

health care workers

in emergency

department in

Ismailia, Egypt

12 Liu et al. (2015)

Extent, Nature, an prevalence and

China

ina

\section{Cut}

Latitude

China

Cut

Latitude

Northastern Cut China Latitude

Cut Risk Factors of Workplace Violence

Provinsi

in Public Teriary

Hospitals in China:
Of 1,932 participants, 68.6\% had experienced violence at work. Violence was mostly done by patients' families. Factors that have a significant influence were the level of education, profession, department, work experience, time of care, direct service to patients, gender, and income.

From a total of 15,970 participants, the prevalence of violence in the workplace was $65.8 \%$. The most common type of violence was verbal violence. Violence was most often done by patients' relatives. Some factors that have a signifycant influence were age, department, work experience, and direct interaction with patients.

Of the total sample of 1,899 people, $83.3 \%$ had experienced violence at work. Some factors that have a signifycant influence on workplace violence were gender, education, age, occupation, anxiety, professional titles, and shift work systems.

From a total of 134 participants, $58.2 \%$ had experienced violence. Most participants did not report to the hospital authority. Some factors that have a significant influence were work, age, work experience, and marita status.

Medical staff have a high risk of experiencing violence at the Children's Hospital in China. Preparation of preventative measures are needed, such as drafting regulations, developing policies and strategies to prevent violence in hospitals, and hospital managers need to provide psychological support for victims.

Workplace violence is often found in Tertiary and Country Hospitals in China. It is necessary to develop effective control strategies at the individual, hospital and national levels.

The healthcare profession in hospitals is a profession that is vulnerable to experience violence at work in China. This problem cannot be underestimated. The issue of discussing strategies to prevent and intervene in acts of violence needs to be studied and implemented.

Workplace violence is a problem experienced by health workers in the emergency department. Protocol development to report, recognize, handle, and develop strategies in dealing with violence in the workplace are required.

From the total of 1,129 participants, 35.4\% experienced physical violence at Specialist Hospitals and $76 \%$ experienced non-physical violence at General Hospitals. Some factors that have a significant influence were lack of
Preventive action is not only on departments in hospitals that have a high risk. Hospital management should provide an education program for those with high risk and follow up to provide support to employees and

The $6^{\text {th }}$ International Conference on Public Health Best Western Premier Hotel, Solo, Indonesia, October 23-24, 2019 | 151

https://doi.org/10.26911/the6thicph-FP.02.05 


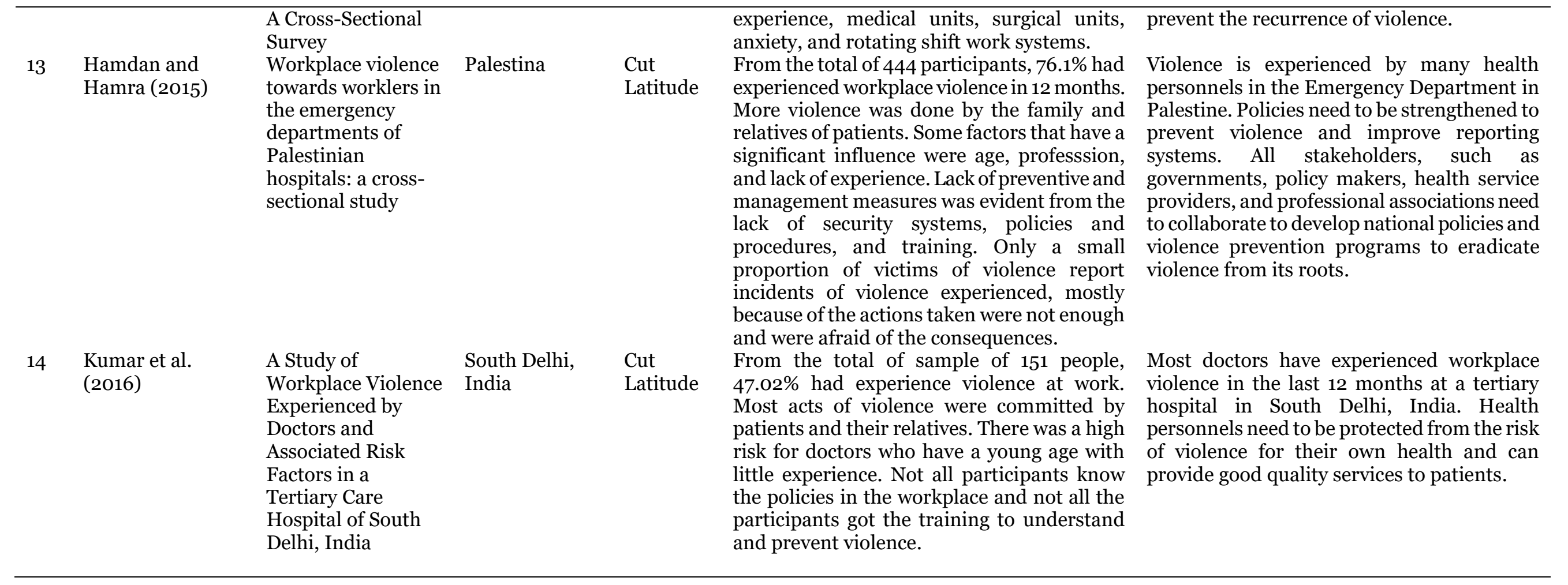

The $6^{\text {th }}$ International Conference on Public Health Best Western Premier Hotel, Solo, Indonesia, October 23-24, $2019 \mid 152$

https://doi.org/10.26911/the6thicph-FP.02.05 


\section{DISCUSSIONS}

From the articles found, it was known that the factors that have a significant influence on workplace violence in most articles are profession, age, shift work system, and work experience. Based on The Joint Commission (2018), professional factors in the health sector are one of the causes of violence.

Based on studies from the American Nurse Association, it is known that over a period of three years, there were $25 \%$ of nurses and nursing students experiencing physical violence by patients or relatives of patients. General practitioners who work in the Emergency Department also have the risk of experiencing violence. Health personnels who have a younger age also have a higher risk due to lower education levels. In addition, younger age was also associated with a lack of experience, so the ability to deal with violent incidents becomes weaker (Zainal et al., 2018). Health personnels who work in shifts have a higher risk of experiencing violence due to lower job control, lack of fairness at work, and insecurity at work (Niu et al., 2019).

Most of health personnels who experienced violent incidents did not report violence. Some causes of reporting were not carried out due to the assumption that reporting actions were an inefficient action (Al Turki et al., 2016), unimportant, and afraid of consequences (Xing et al., 2015). Some of these reasons were causes of violence seen from the side of the victim. The cause of the lack of reporting actions from the Hospital side was due to lack of understanding of the procedure (Xing et al., 2017; Kremic et al., 2017).

Reporting incidents of violence can be a protective factor in health workers experiencing psychological violence (Xing et al, 2015). One way that can be done to resolve the problem of violence in the workplace is to increase encouragement and increase awareness to report incidents of violence experien- ced. Delays in reporting verbal abuse events can lead to physical violence.

Health service institutions need to develop policies, procedures, and intervenetion strategies adopted by health service institutions (Xing et al., 2015). Steps that can be taken was to conduct training related to violence and psychological endurance from health service institutions to health personnels as a form of mitigating negative impacts. Interventions that aim to reduce workplace violence need to be adjusted to the type of violence, the profession of health personnels, or other factors because violence experienced by health personnels was not always caused by the same reason (Sun et al., 2017). National policies need to be prepared by the Government, policy makers, and service providers in overcoming problems of violence in the workplace (Hamdan and Hamra, 2015).

Workplace violence was often experienced by health personnels. Factors that have a major influence on incidents of violence were health professions, age, shift systems, and work experience. Knowing the factors that have a significant influence can be a reference to make improvements to management such as the formulation of strategies to develop policies in preparing procedures that facilitate the reporting of violent incidents, and formulating an effective intervention to deal with violence in the workplace.

\section{REFERENCES}

Abdella RF, Salama KM (2017). Prevalence and risk factors of workplace violence against health care workers in emergency department in Ismailia, Egypt. Pan African Medican Journal; 26: 21.

Aksakal FNB, karasahin EF, Dikmen AU, Avci E, Ozkan S (2015). Workplace physical violence, verbal violence, and mobbing experienced by nurses at a university hospital. Tubitak, 45: 13601368. 
Al-Turki N, Afify AM, alateeq M (2016). Violence against health workers in Family Medicine Centers. Journal of Medicine Healthcare, 9: 257-266.

Cheung T, Lee PH, Yip PSE (2017). Workplace Violence toward Physicians and Nurses: Prevalence and Correlates in Macau. International Journal of Environmental Research and Public Health, 14: 879

Cheung T, Yip PSE (2017). Workplace Violence towards Nurses in Hongkong: prevalence and correlates. BMC Pulic Health, 17: 196.

Hamdan M, Hamra AA (2015). Workplace violence towards worklers in the emergency departments of Palestinian hospitals: a cross-sectional study Human resources for health, 13: 28.

Kocabiyik N, Yildirim S, Turgut EO, Turk MK, Ayer A (2015). A study of the frequency of violence to healthcare professionals in mental health hospital and lated factors. Dusunen Adam the Journal of Psychiatry and Neurogical Sciences, 28: 112-118.

Kremic MBF, Terzic-Supic ZC, Santric-Milicevic MM, Trajkovic GZ (2017). Enouraging employees to report verbal violence in primary health care in Serbia: A cross-sectional study. Zdr Varst; 56(1): 11-17.

Kumar M, Verma M, Das T, Pardeshi G, Kishore J, Padmanandan (2016). Journal of Clincial Diagnostic and Research 10(11): 6-10.

Li P, Xing K, Qiao H, Fang H, Ma H, Jiao M, Hao Y et al., (2018). Physical violence against general practicioners and nurses in Chinese township hospitals: incidence and implications. Health and Quality of Life Outcomes 16: 117.

Li Z, Yan C, Shi L, Mu H, Lin X, Li A, Zhao C et al. (2017). Workplace violence again- st medical staff of Chinese children's hospitals: A cross-sectional study PLoS One, 12(6): eo179373.

Liu H, Zhao S, Jiao M, Wang J, Peters DH, Qiao H, Zhao Y et al., (2015). Extent, Nature, and Risk Factors of Workplace Violence in Public Teriary Hospitals in China: A Cross-Sectional Survey. Int. J. Environ. Res. Public Health, 12: 68016817.

Niu SF, Kuo SF, Tsai HT, Kao CC, Traynor T, Chou KR (2019). Prevalence of workplace violent episodes experienced by nurses in acute psychiatric settings plos ONE 14(1): eo211183.

Shi L, Zhang D, Zhou C, Yang L, Sun T, Hao $T$, Peng $X$ et al., (2017). A cross-sectional study on the prevalence and associated risk factors for workplace violence against Chinese nurses BMJ Open; 7: e01305.

Sun P, Zhang X, Sun Y, Ma H, Jiao M, Xing K, Kang Z et al., (2017). Workplace violence against health care workers in north Chinese hospitals: A cross-sectional survey. Int. J. Environ. Res. Public Health, 14: 96.

The Joint Comission (2018). Physical and verbal violence against health care workers. The Joint Comission. https://www.jointcommission.org/assets/1/18/SEA_59_Workplace_violence_4_1 3_18_FINAL.pdf. Xing K, Jiao M, Ma H, Qiao H, Hao Y, Li Y, Gao L et al. (2015). Physical violence against general practicioners nurses in Chinese township hospitals: a cross-sectional survey. PLoS ONE 10(11): e0142954.

Zainal N, Rasdi I, Saliludin SM (2018). The risk factors of workplace violence ong healthcare orkers in public hospital. Malaysian Journal of Medicine and Health Sciences 14 (SP2): 120-127 